\title{
EL ÁREA DE HISTORIA DEL DERECHO, A 75 AÑOS DE LA FUNDACIÓN DEL INSTITUTO DE INVESTIGACIONES JURÍDICAS DE LA UNAM
}

\author{
Oscar CRUZ BARNEY*
}

\begin{abstract}
SUMARIO: I. Las áreas de investigación del Instituto de Investigaciones Jurídicas. II. El Instituto de Investigaciones Jurídicas y la historia del derecho en México. III. Publicaciones de historia del derecho del Instituto de Investigaciones Jurídicas. IV. A manera de conclusión. El papel del Instituto de Investigaciones Jurídicas en el estudio y difusión de la historia del derecho.
\end{abstract}

\section{LAS ÁREAS DE INVESTIGACIÓN DEL INSTITUTO DE INVESTIGACIONES JURÍDICAS}

Partiendo de un principio básico de respeto a la libertad de investigación, examen y discusión de las ideas, los investigadores del Instituto de Investigaciones Jurídicas desarrollan su tarea científica organizados en nueve áreas de investigación más un núcleo de investigación interdisciplinario. A cada área le corresponde un investigador responsable de la coordinación del trabajo académico.

Las áreas de investigación del Instituto son: Derecho administrativo, Derecho ambiental, Derecho civil y mercantil, Derecho constitucional, Derecho de la información, Derecho fiscal, Derecho internacional, Derecho penal, Derecho procesal, Derecho social, Filosofía y teoría del derecho, Historia

* Cruz Distinguida de Primera Clase de la Orden de San Raimundo de Peñafort. Cruz de San Ivo del Real e Ilustre Colegio de Abogados de Zaragoza. Gran Cruz al Mérito en Servicio a la Abogacía del Consejo General de la Abogacía Española. Académico de Número de la Academia Mexicana de Jurisprudencia y Legislación. 
del derecho, Investigación aplicada y opinión, Núcleo de estudios en salud y derecho y Sociología del derecho.

Existen además líneas de investigación que son:

- Derechos, conflictos sociales y política

- Derechos, migraciones y movilidades

- Derecho romano y tradición romanista

- Derecho y economía informal

- Metodología de la investigación jurídica y enseñanza del derecho

- Materia energética

- Hacia un Estado de derecho internacional

- Instituciones, representación política y democracia

- Regulación y derecho económico

- Promoción y protección de los derechos de la infancia

- Sistema penal acusatorio en México

- Transparencia legislativa, rendición de cuentas y democracia.

\section{El InSTItUto De Investigaciones JuRÍdicas Y LA HISTORIA DEL DERECHO EN México}

El interés por la historia del derecho en el Instituto de Investigaciones Jurídicas ha estado siempre presente, la realización en 1975 y publicación posterior en 1976 del IV Congreso Internacional de Historia del Derecho Indiano ${ }^{1}$ lo acredita, logrado gracias al apoyo y ayuda del Instituto. ${ }^{2}$ Las publicaciones dedicadas a temas histórico-jurídicos o la publicación de ediciones facsimilares por la institución ha sido constantes.

Asimismo el apoyo brindado para la celebración de los congresos de Historia del Derecho Mexicano y de un ulterior Congreso de Historia del Derecho Indiano ha sido constante. Lo atestiguan las memorias correspondientes publicadas en forma individual o en el Anuario Mexicano de Historia del Derecho. ${ }^{3}$

1 Memoria del IV Congreso del Instituto Internacional de Historia del Derecho Indiano, México, UNAM, Facultad de Derecho, 1976.

2 Zavala, Silvio, "Los congresos de historia del derecho mexicano y el nacimiento del Anuario", Anuario Mexicano de Historia del Derecho, México, UNAM, Instituto de Investigaciones Jurídicas, 1989, t. I, p. 340.

3 Memoria del III Congreso de Historia del Derecho Mexicano, coord. por José Luis Soberanes, México, UNAM, 1984; Memoria del IV Congreso de Historia del Derecho Mexicano, coord. por Beatriz Bernal, México, UNAM, Instituto de Investigaciones Jurídicas, 1988, 2 ts.; Anuario Mexicano de Historia del Derecho. Memorias del VII Congreso de 
La participación del Instituto de Investigaciones Jurídicas ya sea en forma institucional o a través de sus investigadores en los congresos de Historia del Derecho Mexicano ha sido una constante. Iniciados en $1981,{ }^{4}$ bajo los impulsos de Guillermo Floris Margadant, el XI Congreso de Historia del Derecho Mexicano fue organizado por la Universidad de Guanajuato, el Instituto de Investigaciones Jurídicas de la UNAM y el Ilustre y Nacional Colegio de Abogados de México en noviembre de 2014. Es, sin duda, tiempo ya de preparar el XII Congreso de Historia del Derecho Mexicano.

Hacia 1965, las áreas del Instituto, entonces secciones, eran Derecho público, Derecho privado, Derecho procesal y Derecho internacional. ${ }^{5}$ Cabe destacar que en los primeros 25 años del Instituto de Derecho Comparado de México solamente se publicó un título de Historia del derecho bajo la ya creada Serie C) Estudios Históricos que incluía "trabajos que sin tener un carácter iuscomparatista estricto, contienen no obstante un material de información interesante sobre instituciones jurídico-políticas del México histórico, que puede auxiliar al investigador jurista en estudios posteriores de aquel carácter". ${ }^{6}$ Se trata del magnífico trabajo de Miranda, Las ideas y las instituciones políticas mexicanas, ${ }^{7}$ que habría de publicarse posteriormente en 1978 en edición facsimilar, con prólogo y notas de Andrés Lira.

Historia del Derecho Mexicano, México, UNAM, Instituto de Investigaciones Jurídicas, núm. X, 1998; Anuario Mexicano de Historia del Derecho. Memorias del VIII Congreso de Historia del Derecho Mexicano, México, UNAM, Instituto de Investigaciones Jurídicas, núm. XVIII, 2006, y Anuario Mexicano de Historia del Derecho. Memorias del IX Congreso de Historia del Derecho Mexicano, México, UNAM, Instituto de Investigaciones Jurídicas, núm. XX, 2008.

4 Véase Memoria del Primer Congreso de Historia del Derecho Mexicano, coord. por Beatriz Bernal, México, UNAM, 1981.

5 Seara Vázquez, Modesto, "Propósitos y funciones del Instituto de Derecho Comparado de México", en Alcalá-Zamora y Castillo, Niceto (ed.), XXV Aniversario del Instituto de Derecho Comparado de México (1940-1965). Historia, actividades, crónica de las bodas de plata, México, UNAM, 1965, p. 29.

6 Véase Rodríguez García, Fausto E., "Actividad editorial del Instituto de Derecho Comparado de México: 1945-1965”, en Alcalá-Zamora y Castillo, Niceto (ed.), op. cit., p. 47.

7 Miranda González, José, Las ideas y las instituciones politicas mexicanas. Primera parte (1521-1820), México, UNAM, Instituto de Derecho Comparado, 1952, ediciones conmemorativas del IV Centenario de la Universidad de México, vol. XIII, XX-364 pp. De esta publicación daba cuenta don Javier Elola González en su trabajo "Veinticinco años del Instituto de Derecho Comparado de México", en Alcalá-Zamora y Castillo, Niceto (ed.), op. cit. 
Este será el primer texto de historia del derecho publicado por lo que es hoy el Instituto de Investigaciones Jurídicas. Un texto que por su gran calidad daba un muy buen inicio a la cauda de publicaciones históricas que vendrían con el paso de los años.

El Área de Historia del Derecho se crea por oficio circular del director del Instituto de 31 de enero de 1979. Mediante dicho documento se comunicó a la comunidad académica la creación de tres grandes áreas: Derecho público a cargo de Héctor Fix-Zamudio, Historia del derecho a cargo de Jorge Mario García Laguardia y Derecho internacional a cargo de Ricardo Méndez Silva. ${ }^{8}$

Entre 1980 y 1989 las actividades sustantivas del Instituto eran desde luego la realización de investigaciones jurídicas, la impartición de cátedras en licenciatura, maestría y doctorado tanto en la Facultad de Derecho de la UNAM como en otras instituciones públicas y privadas, y la superación y formación de su planta académica. ${ }^{9}$

En la segunda mitad de la década de los ochenta (1986) se inauguraron las instalaciones en la Ciudad de las Humanidades, organizando al año siguiente su actividad académica en cuatro grandes áreas: Derecho público, Derecho privado, Derecho social e informativo, Historia y filosofía del derecho.

El área actualmente está integrada por los doctores José Luis Soberanes Fernández, Adriana Berrueco García, Luis René Guerrero Galván, Jorge Mario Magallón Ibarra y Guillermo José Mañón Garibay.

En 1989, Jorge Madrazo, entonces director del Instituto, afirmaba que en "el Instituto de Investigaciones Jurídicas de la UNAM, el área de historia del derecho ha sido tradicionalmente una de las más amplias y que más reconocimientos nacionales e internacionales ha conquistado para la Institución". ${ }^{10}$

Grandes historiadores del derecho han pasado y/o laboran o se han relacionado con el Instituto a través de sus publicaciones: Jorge Adame, María del Refugio González, Marta Morineau, José de Jesús López Monroy, Guillermo Floris Margadant, José Luis Soberanes, Beatriz Bernal, Silvio Zavala, etc.

8 Véase XL Aniversario del Instituto de Investigaciones Jurídicas, México, UNAM, 1980, p. 15.

9 Reporte institucional, México, UNAM, Instituto de Investigaciones Jurídicas, 1998, p. 4.

10 Madrazo, Jorge, "Presentación”, Anuario Mexicano de Historia del Derecho, México, UNAM, Instituto de Investigaciones Jurídicas, 1989, t. I, p. XIII. 
Bajo la dirección de José Luis Soberanes Fernández (1990-1998), la historia del derecho en el Instituto vivió un gran impulso. Se publicaron múltiples investigaciones y se dieron a luz diversas ediciones facsimilares de gran importancia, marcando sin duda una época en la materia en nuestro país.

Diego Valadés mantuvo el entusiasmo y apoyó a la historia del derecho, tarea que continuó con gran interés Héctor Fix-Fierro, lo cual se reflejó con la celebración de dos congresos de contenido histórico-jurídico. El primero, en abril de 2009, dedicado a los 120 años de la publicación del Código de Comercio de 1889, conjuntamente entre el Tribunal Superior de Justicia del Distrito Federal y el Ilustre y Nacional Colegio de Abogados de México, cuyas memorias fueron publicadas. ${ }^{11} \mathrm{El}$ segundo, en octubre del mismo año, sobre los abogados y la formación del Estado mexicano, organizado por el Instituto de Investigaciones Históricas y el Ilustre y Nacional Colegio de Abogados de México: sus memorias también fueron publicadas.

Se sostiene que "es verdad que el impulso renovador de la historia del derecho en México provino, primero, de la Facultad de Derecho de la UNAM y, después, del Instituto de Investigaciones Jurídicas de la misma universidad, gracias a la presencia magisterial y directora del doctor Guillermo Floris Margadant". ${ }^{12}$

La investigación en historia del derecho llevada a cabo en el Instituto se desarrolla, enriquece y completa con los trabajos de historiadores del derecho como Andrés Lira González, Jaime del Arenal Fenochio, Alejandro Mayagoitia, Rafael Diego Fernández Sotelo, Marco Antonio Pérez de los Reyes, Rigoberto Ortiz Treviño, José Ramón Narváez Hernández, Juan Pablo Pampillo, Rafael Estrada Michel, Salvador Cárdenas Gutiérrez, Juan Carlos Abreu y Abreu, Juan Pablo Salazar Andreu y José Enciso Contreras.

\section{Publicaciones De Historia Del DeReCho DEL InSTItUTO DE INVESTIGACIONES JURÍDICAS}

El buque insignia de la historia del derecho en el Instituto de Investigaciones Jurídicas fue el Anuario Mexicano de Historia del Derecho (ahora Revista

11 Cruz Barney, Oscar (coord.), 120 años del Código de Comercio. Codificación y descodificación mercantil en México, México, Ilustre y Nacional Colegio de Abogados de México-Tribunal Superior de Justicia del D. F.-UNAM, Instituto de Investigaciones Jurídicas, 2009.

12 Arenal Fenochio, Jaime del, "La escuela mexicana de historiadores del derecho", Anuario Mexicano de Historia del Derecho, México, UNAM, Instituto de Investigaciones Jurídicas, 2006, t. XVIII, p. 61. 
Mexicana de Historia del Derecho) que se publicó desde 1989, siendo su primera directora técnica Beatriz Bernal.

El Anuario inició con un Consejo Editorial y una lista de importantes miembros correspondientes de la revista en el extranjero.

La dirección del Anuario cambió en 1992 con el número IV en el que su nuevo director José Luis Soberanes Fernández habría de dirigirlo con gran éxito hasta 2009 en que deja la dirección y publica el número XXII correspondiente a 2010. Sin duda, la visión de José Luis Soberanes fue fundamental para mantener viva y presente la única publicación periódica que hay en nuestro país dedicada exclusivamente a la historia del derecho.

En 2010, el Anuario pasa a ser Revista Mexicana de Historia del Derecho con periodicidad semestral bajo la dirección de Oscar Cruz Barney, quien dirigió los números correspondientes de 2011 a 2018. En septiembre de 2018 asumió la dirección Luis René Guerrero Galván.

Su Consejo Editorial se integra por Silvio Zavala, María del Refugio González, Andrés Lira González, José de Jesús López Monroy, Jorge Adame, Jaime del Arenal Fenochio, Alejandro Mayagoitia, Rafael Diego Fernández Sotelo, Marco Antonio Pérez de los Reyes, Salvador Cárdenas Gutiérrez y José Enciso.

El Comité Editorial lo componen José Antonio Caballero, Rigoberto Ortiz Treviño, José Ramón Narváez Hernández, Juan Pablo Pampillo, Rafael Estrada Michel, Juan Carlos Abreu y Abreu, Juan Pablo Salazar Andreu, Juan Ricardo Jiménez Gómez, Jesús Antonio de la Torre Rangel, María Audry Luer y Fernando Marcín Balsa.

Los miembros correspondientes de la Revista en el extranjero son Linda Arnold (Estados Unidos), Ana Barrero (España), Beatriz Barrios (España), Beatriz Bernal (España), Bernardino Bravo Lira (Chile), Antonio Dougnac (Chile), José A. Escudero (España), Alberto de la Hera (España), Abelardo Levaggi (Argentina), Jorge Luján (Guatemala), José M. Mariluz Urquijo (Argentina), Rosa M. Martínez de Codes (España), Euardo Martiré (Argentina), Arturo Muro Romero (España), Mariano Peset (España), José Reig Satorres (Ecuador), Daisy Ripodaz (Argentina), José Sánchez Arcilla (España), Ismael Sánchez Bella (España), Víctor Tau Anzoátegui (Argentina) y Fernando Mayorga García (Colombia).

Los asistentes de la Revista han sido Víctor Esqueda, Marco Antonio García Pérez y Marion de Regules Rivollier.

Como ya señalamos líneas arriba, el Anuario, ahora Revista, ha publicado diversas memorias de los congresos de Historia del Derecho Mexi- 
cano, y de esfuerzos colectivos como fue el simposio internacional "1808: A doscientos años y el origen de los derechos humanos" organizado por el Instituto de Investigaciones Jurídicas y la Comisión Nacional de Derechos Humanos bajo la coordinación de José Luis Soberanes.

Durante sus primeros 22 años de vida, el Anuario Mexicano de Historia del Derecho ha dado cabida a estudios, no solamente de derecho mexicano, sino de otras latitudes y sistemas jurídicos. El Derecho romano, castellano, indiano, Ius Commune, la codificación del derecho y la abogacía han transitado por sus páginas. Se busca que la publicación sea un foro de discusión y análisis histórico-jurídico.

Bajo nuestra dirección se crea la colección Publicaciones de la Revista Mexicana de Historia del Derecho, en donde han aparecido los siguientes títulos:

Cruz Barney, Oscar et al., Código Civil para el gobierno interior del Estado de los Zacatecas, 1 de diciembre de 1829, México, UNAM, Instituto de Investigaciones Jurídicas, 2012.

Vallejo García-Hevia, José María, Vasco Núñez de Balboa. Reflexiones sobre su proceso, condena y muerte (1509-1519), México, UNAM, Instituto de Investigaciones Jurídicas, 2015.

García-Molina Riquelme, Antonio M., Las hogueras de la Inquisición en México, México, UNAM, Instituto de Investigaciones Jurídicas, 2016.

Cabe destacar que, con motivo de las fiestas del bicentenario del inicio del movimiento de 1810 y del centenario de la Revolución, se preparó una colección con la LXI Legislatura del Senado de la República dedicada a la historia de las instituciones jurídicas de los estados de la República. ${ }^{13} \mathrm{Se}$ trata de un atinado esfuerzo por dotar a las entidades federativas de una historia jurídica local, la primera en muchos casos no dedicada estrictamente al ámbito constitucional.

Las publicaciones del Instituto acerca de historia del derecho se han dividido en $a$ ) Fuentes $b$ ) Facsímiles, $c$ ) Estudios, $d$ ) Obras colectivas, antologías, memorias de congresos, simposios y seminarios, y e) Bibliotheca Iuridica Latina Mexicana. A lo cual hay que sumar la colección Publicaciones de la Revista Mexicana de Historia del Derecho. El listado completo se incluye en las siguientes páginas.

13 Coordinados por Patricia Galeana y Daniel Barceló. 


\section{a) Fuentes}

Altamira y CReVea, Rafael, Diccionario castellano de palabras jurídicas y técnicas tomadas de la legislación indiana, 1a. reimp., 1987, 395 pp.

Álvarez de Lara, Rosa María (pres. y coord.), Acervo Silvio Zavala, 1a. reimp., 2004, XXIX-600 pp.

ARNold, Linda (transcriptora), Archivo de la Suprema Corte. Inventario del Archivo del Tribunal de Guerra y Marina, 1816-1854, 1996, XIII-291 pp.

Barragán Barragán, José, Algunos documentos para el estudio del origen del juicio de amparo, 1812-1861, 1a. reimp., 1987, 295 pp.

Barragán Barragán, José, Primera Ley de Amparo de 1861, 1a. reimp., 1987, 222 pp.

Barragán Barragán, José, Proceso de discusión de la Ley de Amparo de 1869, 1a. reimp., 1987, 330 pp.

Barragán Barragán, José, Proceso de discusión de la Ley de Amparo de 1882, 1993, $653 \mathrm{pp}$.

Carbonell, Miguel et al. (comps.), Constituciones históricas de México, 2a. ed., coedición con Porrúa, 2004, XVIII-556 pp.

Cruz Barney, Oscar y Soberanes Fernández, José Luis, Diccionario de historia del derecho, México, UNAM, Instituto de Investigaciones Jurídicas, 2015.

Denegre Vaught Alcocer, Ramiro (comp.), Discursos patrióticos a la Batalla del 5 de mayo de 1862: colección Jorge Denegre Vaught Peña, México, UNAM, Instituto de Investigaciones Jurídicas, 2012.

Denegre Vaught Alcocer, Ramiro (comp.), Discursos patrióticos de la consumación de Independencia de México, 1821: colección Jorge Denegre Vaught Peña, México, UNAM, Instituto de Investigaciones Jurídicas, 2014.

Denegre Vaught Alcocer, Ramiro (comp.), Dos siglos de discursos patrióticos: colección Jorge Denegre Vaught Peña, México, UNAM, Instituto de Investigaciones Jurídicas, 2011.

GonzÁLez, María del Refugio (est. prel. y ed.), Ordenanzas de la minería de la Nueva España formadas y propuestas por su Real Tribunal, 1996, $477 \mathrm{pp}$.

GonZÁLEZ Oropeza, Manuel (comp.), La centenaria obra de Ignacio L. Vallarta como gobernador de Jalisco, 1995, $835 \mathrm{pp}$.

GonzÁlez Oropeza, Manuel (est. introd. y comp.), El siglo diez y nueve de Francisco Zarco y su pensamiento constitucional, 1994, 265 pp. 
González Oropeza, Manuel (est. introd. y comp.), La reforma del Estado federal. Acta de Reformas de 1847, 1998, 932 pp.

González Oropeza, Manuel (introd. y comp.), Homenaje al Congreso Constituyente de Querétaro, 1998, 255 pp.

Guiot de la Garza, Lilia, Catálogo de disposiciones legislativas, de administración y de gobierno de la ciudad de México (1821-1855), coedición con el Departamento del Distrito Federal, 1997, XXIII-119 pp.

Iglesias GonzÁLEZ, Román (introd. y recop.), El pensamiento de Antonio Díaz Soto y Gama a través de 50 años de labor periodística, 1899-1949, 1997, 478 pp.

Iglesias GonzÁlez, Román (introd. y recop.), Planes políticos, proclamas, manifiestos y otros documentos de la Independencia al México moderno, 1812-1940, 1998.

Labastida, Horacio, Guía bibliográfica, cronológica y temática de los debates del Senado en las sesiones públicas y secretas 1824-1853, 1997, $973 \mathrm{pp}$.

Labastida, Horacio, Guía hemerográfica de los debates del Senado en las sesiones públicas ordinarias y extraordinarias, 1824-1853, 1995, $200 \mathrm{pp}$.

León PINelo, Antonio de, Recopilación de las Indias, coedición con Miguel Ángel Porrúa, 1992, 3 ts. (t. I, 1026 pp.; t. II, 971 pp.; t. III, 1082 pp.).

Lope y Vergara, Félix, Diccionario alfabético legislativo del comercio de Filipinas y Nueva España, est. introd. y notas de Ramón Sánchez Flores, 1981, 149 pp.

Maniau, Joaquín, Compendio de historia de la Real Hacienda de la Nueva España, notas y comentarios de Alberto M. Carreño, 1995, 149 pp.

Morales Becerra, Alejandro (comp.), México: una forma republicana de gobierno, vol. II: La forma de gobierno en los Congresos Constituyentes de México, 1995, t. I, 817 pp.

Morales Becerra, Alejandro (comp.), México: una forma republicana de gobierno, vol. II: La forma de gobierno en los Congresos Constituyentes de México, 1995, t. II, 785 pp.

Olea, Héctor R., Sinaloa a través de sus Constituciones, 1985, 351 pp.

Rodríguez de SAN Miguel, Juan N., Escritos jurídicos (1839-1863). Antología, 1992, $220 \mathrm{pp}$.

Soberanes Fernández, José Luis (comp. y est. prel.), Memorias de la Secretaría de Justicia, 1997, 534 pp.

Soberanes Fernández, José Luis y Vega Gómez, Juan Manuel, El Tratado de Guadalupe Hidalgo en su sesquicentenario, 1998, 61 pp. 
Solano, Francisco de, Cedulario de tierras. Compilación. Legislación agraria colonial (1497-1820), 2a. ed., 1991, 587 pp.

Zavala, Silvio, Suplemento documental y bibliográfico a la encomienda indiana, 1994, 469 pp.

\section{b) Facsímiles}

Actas constitucionales mexicanas 1821-1824, est. prel. de José Barragán Barragán, 1980, 9 ts.

Actas constitucionales mexicanas 1821-1824, est. prel. de José Barragán Barragán, 1981, t. X, VII-284 pp.

Álvarez, José María, Instituciones de derecho real de Castilla y de Indias, ed. facs. de la reimpr. mexicana de 1826; est. prel., fuentes y bibliografía de Jorge Mario García Laguardia y María del Refugio González, 1982, 2 ts.

ANónimo, Libro de los principales rudimentos tocante a todos juicios, criminal, civil y executivo, año de 1764, transcripción y est. prel. de Charles R. Cutter, 1994, $81 \mathrm{pp}$.

Castillo Velasco, José María del, Ensayo sobre el derecho administrativo mexicano, 1994, t. I, 483 pp.

Castillo Velasco, José María del, Ensayo sobre el derecho administrativo mexicano, 1994, t. II, 340 pp.

El derecho. Periódico de Jurisprudencia y Legislación 1868-1897, 1a. época, 1a. reimp., coedición con la Suprema Corte de Justicia de la Nación, 2004, t. I al VIII.

ESCRICHE, Joaquín, Diccionario razonado de legislación civil, penal, comercial y forense, con citas del derecho, notas y adiciones por el licenciado Juan Rodríguez de San Miguel, 2a. reimp., ed. y est. introd. por María del Refugio González, coedición con Miguel Ángel Porrúa, 1998, 738 pp.

Rodríguez de San Miguel, Juan, Pandectas Hispano-Megicanas, 2a. ed. facs. tomada de la de 1852, con est. prel. de María del Refugio González, 1992.

Soberanes Fernández, José Luis (ed.), Curia Filípica mejicana, coedición con Porrúa, 1991, XIII-790 pp.

Ventura Beleña, Eusebio, Recopilación sumaria de todos los autos acordados de la Real Audiencia y Sala del Crimen de esta Nueva España, 2a. ed. facs. tomada de la de 1787, con est. prel. de María del Refugio González, 1992. 


\section{c) Estudios}

AdAme GodDard, Jorge, Cuatrocientos casos y respuestas de los juristas romanos, México, UNAM, Instituto de Investigaciones Jurídicas, 2013.

AdAME GodDard, Jorge, El matrimonio civil en México (1859-2000), 2004, $\mathrm{XI}-120 \mathrm{pp}$.

Aguayo Spencer, Rafael, Don Vasco de Quiroga. Pensamiento jurídico (Antología), ed. liminar y notas por José Luis Soberanes Fernández; evocación del autor por Antonio Gómez Robledo; coedición con Miguel Ángel Porrúa, 1986, 263 pp.

Aguilar Rivera, José Antonio, El manto liberal. Los poderes de emergencia en México 1821-1876, 2001, 287 pp.

Alcalá-Zamora y Castillo, Niceto, Estudios de teoría general e historia del proceso (1945-1972), 1a. reimp., 1992, 2 ts.; t. I, 628 pp.; t. II, 694 pp.

Arnold, Linda, Política y justicia. La Suprema Corte mexicana (18241855), 1996, $207 \mathrm{pp}$.

Arregui Zamorano, Pilar, La Audiencia de México según los visitadores (siglos XVI y XVII), 2a. ed., 1985, 284 pp.

BARquera, Juan María Wenceslao, Lecciones de política y derecho público para la instrucción del pueblo mexicano, ed. facs. tomada de la de 1822, con est. prel. de Ernesto de la Torre Villar, 1991, 208 pp.

Barragán Barragán, José, El federalismo mexicano. Visión históricoconstitucional, 2007, XI-238 pp.

BARRIEntos Grandón, Javier, La cultura jurídica en la Nueva España, 1994, $286 \mathrm{pp}$.

Bastian, Jean-Pierre, América Latina 1492-1992, conquista, resistencia y emancipación, 1992, 88 pp.

Bernal, Beatriz, Cuba y sus leyes. Estudios histórico-jurídicos, 2002, XII$173 \mathrm{pp}$.

Bernal, Beatriz y LedeSma, José de Jesús, Historia del derecho romano y de los derechos neorromanistas, t. I: De los orígenes a la Alta Edad Media, 7a. ed., coedición con Porrúa, 1997, 440 pp.

Berrueco, Adriana, José María Lafragua: precursor de la protección al patrimonio cultural, México, UNAM, Instituto de Investigaciones Jurídicas, 2013.

Berrueco, Adriana, La cultura y el derecho en México: ciclo juristas académicos mexicanos, México, UNAM, Instituto de Investigaciones Jurídicas, 2014. 
Blanco VAldés, Roberto L., El "problema americano" en las primeras cortes liberales españolas, 1810-1814, 1995, 87 pp.

CABAllero Juárez, José Antonio, El régimen jurídico de las armadas de la Carrera de Indias siglos XVI y XVII, 1997, 385 pp.

Carbonell, Miguel, Historia de los derechos fundamentales, coedición con Porrúa y la Comisión Nacional de los Derechos Humanos, 2005, XXV$266 \mathrm{pp}$.

Carpintero Benítez, Francisco, Historia del derecho natural. Un ensayo, 1999, $352 \mathrm{pp}$.

CARrillo Blouin, Elsa, Los informes presidenciales en México: 1877-1976 ¿Ruptura o continuidad?, 1996, 906 pp.

Carrillo Prieto, Ignacio, Cuestiones jurídico-políticas en Francisco Suárez, 1a. reimp., 1986, 74 pp.

CARrillo Prieto, Ignacio, La ideología jurídica en la constitución del Estado mexicano, 1812-1824, 1a. reimp., 1986, 217 pp.

Castañeda Delgado, Paulino, La teocracia pontifical en las controversias sobre el nuevo mundo, 1996, $632 \mathrm{pp}$.

Cruz Barney, Óscar, Chihuahua. Historia de las instituciones jurídicas, México, UNAM, Instituto de Investigaciones Jurídicas, Senado de la República, 2010.

Cruz BARney, Oscar, Derecho privado y Revolución mexicana, México, Instituto de Investigaciones Jurídicas, UNAM, 2016.

Cruz Barney, Óscar, El comercio exterior de México, 1821-1928, 2005, XII-205 pp.

Cruz Barney, Óscar, El Consulado del Comercio de Puebla. Régimen jurídico, historia y documentos, 1821-1824, 2006, XVI-202 pp.

Cruz BARNEY, Óscar, El corso marítimo. Influencias de la Ordonnance de la Marine de 1681 en el derecho hispanoindiano, México, UNAM, Instituto de Investigaciones Jurídicas, 2009.

Cruz Barney, Óscar, El régimen jurídico de los consulados de comercio indianos: 1784-1795, 2001, 334 pp.

CRUZ BARNEY, Óscar, El régimen jurídico del corso marítimo: el mundo indiano y el México del siglo XIX, 1997, 570 pp.

CRUZ BARNEY, Óscar, El riesgo en el comercio hispano-indiano: préstamos y seguros maritimos durante los siglos XVI a XIX, 1998, 242 pp.

Cruz Barney, Óscar, Historia de la jurisdicción mercantil en México, coedición con Porrúa, 2006, XXX-333 pp.

Cruz Barney, Óscar, La codificación en México: 1821-1917. Una aproximación, 2004, XII-240 pp. 
Cruz Barney, Óscar, La República Central de Félix Zuloaga y el Estatuto Orgánico Provisional de la República de 1858, México, UNAM, Instituto de Investigaciones Jurídicas, 2009.

Cruz Barney, Óscar, La codificación en México, coedición con Porrúa, 2010.

Cruz Barney, Oscar, Una visión indiana de la justicia de la guerra, México, UNAM, Instituto de Investigaciones Jurídicas, 2014.

Dougnac Rodríguez, Antonio, Manual de historia del derecho indiano, $2 \mathrm{a}$. ed., coedición con McGraw-Hill, 1998, 398 pp.

ESQUivel ObRegón, Toribio, Prolegómenos a la historia constitucional de México, ed., pres. y notas de José Luis Soberanes Fernández, 1980, $102 \mathrm{pp}$.

FAIRÉN GUILLÉN, Víctor, Antecedentes aragoneses de los juicios de amparo, 1971, 105 pp.

FERnÁnDEZ RuIz, Jorge, Juárez y sus contemporáneos, 2a. ed., 2006, 407 pp. Ferrer Muñoz, Manuel, La Constitución de Cádiz y su aplicación en la Nueva España, 1993, 310 pp.

Ferrer MuÑoz, Manuel, La formación de un Estado nacional en México. El imperio y la República federal: 1821-1835, 1995, 379 pp.

Ferrer Muñoz, Manuel y Bono López, María, Pueblos indígenas y Estado nacional en México en el siglo XIX, 1998, 700 pp.

Ferrer Muñoz, Manuel y Luna Carrasco, Juan Roberto, Presencia de doctrinas constitucionales extranjeras en el primer liberalismo mexicano, 1996, 377 pp.

Fuentes LóPez, Carlos, El racionalismo jurídico, 2003, 274 pp.

Friedman, Lawrence M., Breve historia del derecho estadounidense, trad. y comentario de Pablo Jiménez Zorrilla, México, UNAM, 2007.

García Laguardia, Jorge Mario y Pantoja Morán, David, Tres documentos constitucionales en la América española preindependiente, 1975, $120 \mathrm{pp}$.

García-Gallo y de Diego, Alfonso, Atlas histórico-jurídico, coedición con Miguel Ángel Porrúa y la Procuraduría General de Justicia del Distrito Federal, 1997, 511 pp.

García-Molina RiQuelme, Antonio M., El régimen de penas y penitencias en el Tribunal de la Inquisición de México, 1999, XXXVIII-679 pp.

GonzÁlez Oropeza, Manuel, El federalismo, 1995, 760 pp.

Gómez Robledo, Antonio, El ius cogens internacional. Estudio históricocrítico, 1a. reimp., 2003, XII-195 pp. 
Gómez Robledo, Antonio, Fundadores del derecho internacional (Vitoria, Gentili, Suárez, Grocio), 1986, 181 pp.

González, María del Refugio, El derecho civil en México, 1821-1871. Apuntes para su estudio, 1988, 197 pp.

GonzáLEz, María del Refugio, El derecho indiano y el derecho provincial novohispano. Marco historiográfico y conceptual, 1995, 77 pp.

GonzáLEZ, María del Refugio, Estudios sobre la historia del derecho civil en México en el siglo XIX, 1981, 130 pp.

GonzáLez, María del Refugio, Historia del derecho mexicano, 2a. ed., 1983, $106 \mathrm{pp}$.

GonzÁlez, María del Refugio, Historia del derecho mexicano, 2a. reimp., coedición con McGraw-Hill, 1999, colección Panorama del Derecho Mexicano, $130 \mathrm{pp}$.

GüERECA Durán, Raquel E., Milicias indígenas en la Nueva España. Reflexiones del derecho indiano sobre los derechos de guerra, 2016, 259 pp. GuERrERo, Omar (comp.), El papel de los ministerios de justicia en la reforma del Estado, 1998, 187 pp.

Guerrero, Omar, La Secretaría de Justicia y el Estado de derecho en México, 1996, $322 \mathrm{pp}$.

Guerrero Galván, Luis René, Lecciones de derecho indiano: un manual práctico para su enseñanza, coedición con Porrúa, 2016.

Guerrero Galván, Luis René y Guerrero Galván, Alonso, Los tarascos y la Relación de Michoacán de fray Jerónimo de Alcalá: manuales para entender el derecho prehispánico, México, UNAM, Instituto de Investigaciones Jurídicas, 2015.

Ibarra Palafox, Francisco A. (comp.), El Congreso de Anáhuac y la Constitución de Apatzingán: obra documental, México, UNAM, Instituto de Investigaciones Jurídicas, 2016.

Labastida, Horacio, Belisario Domínguez y el Estado criminal 1913-1914, coedición con Siglo XXI Editores, 2002, 259 pp.

LóPez Betancourt, Raúl Eduardo, El antifederalismo de Carlos María de Bustamante, 1997, $176 \mathrm{pp}$.

LóPez Betancourt, Raúl Eduardo, Carlos María de Bustamante, legislador (1822-1824), 1991, 277 pp.

LuCERo ANTUNA, Héctor, Evolución político-constitucional de Baja California Sur, 1979, 198 pp.

Magallón Ibarra, Jorge Mario, El renacimiento medieval de la jurisprudencia romana, 2002, XXII-245 pp. 
MAgallón IBARRA, Jorge Mario, La senda de la jurisprudencia romana, 2000, XVII-296 pp.

Magallón Ibarra, Jorge Mario, Proceso y ejecución vs. Fernando Maximiliano de Habsburgo, 2005, XXI-639 pp.

Malagón, Javier y Zavala, Silvio, Rafael Altamira y Crevea. El historiador y el hombre, 1a. reimp., 1987, $140 \mathrm{pp}$.

Maranini, Giuseppe, Historia del poder en Italia, trad. de Miguel Ángel González Rodríguez y María Cristina Pestellini-Laparelli Salamon, 1985, $542 \mathrm{pp}$.

Margadant S., Guillermo F., El viejo Burke y el nuevo liberalismo, coedición con la Universidad Autónoma de Tlaxcala, 1994, 159 pp.

Margadant S., Guillermo F., Introducción a la historia del derecho mexicano, 1971, $268 \mathrm{pp}$.

Mariel de IbáÑEz, Yolanda, El Tribunal de la Inquisición en México (siglo XVI), 2a. ed., coord. por José Luis Soberanes Fernández, 1979, 100 pp.

MARTínez DE CODES, Rosa María, Los bienes nacionales de origen religioso en México, 1833-2004: estudio histórico-jurídico, México, UNAM, Instituto de Investigaciones Jurídicas, 2007.

McAlister, Lyle N., El fuero militar en la Nueva España (1764-1800), trad. de José Luis Soberanes Fernández, 1982, 119 pp.

Miranda González, José, Las ideas y las instituciones políticas mexicanas. Primera parte (1521-1820), 1952, vol. XIII, XX-364 pp. (ed. facs. con pról. y notas de Andrés Lira, 1978).

Moctezuma Barragán, Javier, José María Iglesias y la justicia electoral, 1994, 447 pp.

Montero Aroca, Juan, La herencia procesal española, 1994, 104 pp.

Moreno BonetT, Margarita, Los derechos humanos en perspectiva histórica. De los derechos individuales a los sociales 1857-1917, 2005, XIV$348 \mathrm{pp}$.

Noriega CANTú, Alfonso, Los derechos sociales; creación de la Revolución de 1910 y la Constitución de 1917, coedición con la Facultad de Derecho de la UNAM, 1989, 126 pp.

NoRIEGa CANTÚ, Alfonso, El pensamiento conservador y el conservadurismo mexicano, 1994, 2 ts.; t. I, 263 pp.; t. II, 265-539 pp.

PANTOJa Morán, David, La Asamblea Nacional Francesa de 1789-1791 y la invención de la Constitución, México, UNAM, Instituto de Investigaciones Jurídicas, 2017. 
Patiño Gutiérrez, Carlos, La validez del derecho en la escolástica. Desobediencia, iusnaturalismo y libre albedrío en Francisco Suárez, México, UNAM, Instituto de Investigaciones Jurídicas, 2017.

Paoli Bolio, Francisco, La Constitución de Cádiz en Iberoamérica, México, UNAM, Instituto de Investigaciones Jurídicas, 2016.

Pérez Collados, José María, Los discursos políticos del México originario, 1999, $317 \mathrm{pp}$.

Pérez Fernández del Castillo, Bernardo, Historia de la escribanía en la Nueva España y el notariado en México, 1983, 175 pp.

Piña GutiÉrRez, Jesús Antonio, Antecedentes y evolución del Poder Legislativo en Tabasco, 1824-1914, México, UNAM, Instituto de Investigaciones Jurídicas, Universidad Juárez Autónoma de Tabasco, 2011.

Porras MuÑoz, Guillermo, Iglesia y Estado en Nueva Vizcaya (1562-1821), 2a. ed., 1980, $558 \mathrm{pp}$.

RABASA, Emilio O., El pensamiento político del Constituyente de 1856-1857, pról. de Andrés Serra Rojas, coedición con Porrúa, 1991, XXVII-192 pp.

Rabasa, Emilio O., El pensamiento político del Constituyente de 1824. Integración y realización, 1986, $142 \mathrm{pp}$.

Rabasa, Emilio O., El pensamiento politico y social del Constituyente de 1916-1917, 1996, $355 \mathrm{pp}$.

Rabasa, Emilio O., Historia de las Constituciones mexicanas, 1a. reimp. de la 3a. ed., 2004, VI-104 pp.

Rabasa, Emilio O., La evolución constitucional de México, 2004, XXIX$429 \mathrm{pp}$.

Ríos Granados, Gabriela y SANTos Flores, Israel, Breve historia hacendaria de México, México, UNAM, 2013.

Sanciñena Asurmendi, Teresa, La Audiencia en México en el reinado de Carlos III, 1999, 275 pp.

Savigny, Friedrich Karl von, Textos clásicos, est. prel. de Agustín Squella, coedición con Porrúa, 1981, 91 pp.

SAYEg Helú, Jorge, Introducción a la historia constitucional de México, 1978, $201 \mathrm{pp}$.

Schroeder Cordero, Francisco Arturo, El abogado mexicano, historia e imagen, coedición con el Gobierno del Estado de Guerrero, 1992, 358 pp.

Soberanes Fernández, José Luis, El Poder Judicial federal en el siglo XIX (notas para su estudio), 2a. ed., 1992, 161 pp.

SoberAnes FernándeZ, José Luis, Ensayo bibliohemerográfico y documental de la historia del derecho mexicano, México, UNAM, Instituto de Investigaciones Jurídicas, 2011. 
Soberanes Fernández, José Luis, Evolución de la Ley de Amparo, coedición con la Comisión Nacional de Derechos Humanos, 1994, 442 pp.

Soberanes Fernández, José Luis, Historia del juicio ejecutivo civil, 1977, $112 \mathrm{pp}$.

Soberanes Fernández, José Luis, Historia del sistema jurídico mexicano, 1991, 87 pp.

Soberanes Fernández, José Luis, Los bienes eclesiásticos en la historia constitucional de México, 2000, 104 pp.

Soberanes Fernández, José Luis, Sobre el origen de la Suprema Corte de Justicia de la Nación, con pról. de Héctor Fix-Zamudio, coedición con Miguel Ángel Porrúa, 1987, 85 pp.

Soberanes Fernández, José Luis, Sobre el origen de las declaraciones de derechos humanos, México, UNAM, Instituto de Investigaciones Jurídicas-Comisión Nacional de los Derechos Humanos, 2009.

Soberanes Fernández, José Luis y López Sánchez, Eduardo Alejandro, Vasco de Quiroga en el 450 aniversario de su muerte (1565-2015), México, UNAM, 2017.

TAMayo y Salmorán, Rolando, La ciencia del derecho y la formación del ideal político, 1989, $204 \mathrm{pp}$.

TAMAYO y SAlmorán, Rolando, La jurisprudencia y la formación del ideal político (Introducción histórica a la ciencia jurídica), 1983, 135 pp.

TAMAYo y SALmorán, Rolando, La universidad, epopeya medieval, 3a. ed., 2005, XVIII-148 pp.

TAMAYO Y SALMORÁN, Rolando, Los publicistas medievales y la formación de la tradición política de Occidente, 2005, XXI-239 pp.

Tepaske, John Jay, El Real Protomedicato. La reglamentación de la profesión médica en el imperio español, trad. de José Luis Soberanes Fernández y Miriam de los Ángeles Díaz Córdoba, coedición con la Facultad de Medicina de la UNAM, 1997, 569 pp.

Torre Villar, Ernesto de la, Don Juan de Palafox y Mendoza. Pensador político, 1997, X-108 pp.

TORre Villar, Ernesto de la, Estudios de historia jurídica, 1994, 430 pp.

Torre Villar, Ernesto de la y García Laguardia, Jorge Mario, Desarrollo histórico del constitucionalismo hispanoamericano, 1976, 310 pp.

VÁzQUeZ Alfaro, José Luis, Evolución y perspectiva de los órganos de jurisdicción administrativa en el ordenamiento mexicano, 1992, 294 pp.

VÁzQUez PANDo, Fernando Alejandro, La formación histórica del sistema monetario mexicano y su derecho, 1998, $916 \mathrm{pp}$. 
Vega Vera, David M., México: una forma republicana de gobierno, vol. I: Ideas fundamentales sobre formas de gobierno en México, 1810-1995, 1995, 372 pp.

Vera Estañol, Jorge, La evolución jurídica, pról. de María del Refugio González, 1994, 93 pp.

ViÑAS MeY, Carmelo, El régimen jurídico y la responsabilidad en la América indiana, 2a. ed., 1993, 71 pp.

Zahino Peñafort, Luisa (comp.) El cardenal Lorenzana y el IV Concilio Provincial Mexicano, coedición con Miguel Ángel Porrúa-Universidad de Castilla La Mancha-Cortes de Castilla La Mancha, 1999, 871 pp.

Zahino PeÑafort, Luisa, Iglesia y sociedad en México 1765-1800. Tradición, reforma y reacciones, 1996, $237 \mathrm{pp}$.

Zavala, Silvio, La defensa de los derechos del hombre en América Latina (siglos XVI-XVIII), coedición con UNESCO, 1982, 63 pp.

d) Obras colectivas, antologías, memorias de congresos, simposios y seminarios

Adame GodDard, Jorge (coord.), Derecho civil y romano. Culturas y sistemas jurídicos comparados, 2006, XI-703 pp.

AndRea SÁnchez, Francisco José de (coord.), Derecho constitucional estatal. Estudios históricos, legislativos y teórico-prácticos de los estados de la República mexicana, 2001, XXVIII-254 pp.

Bernal, Beatriz (coord.), Memoria del IV Congreso de Historia del Derecho Mexicano, 1988, t. I, 590 pp.

Bernal, Beatriz (coord.), Memoria del IV Congreso de Historia del Derecho Mexicano, 1988, t. II, 593-1185 pp.

Caballero Juárez, José Antonio y Cruz Barney, Óscar (coords.), Historia del derecho. Memoria del Congreso Internacional de Culturas y Sistemas Jurídicos Comparados, 2005, X-348 pp.

Cienfuegos Salgado, David (coord.), Historia constitucional de las entidades federativas, 2007, XV-1068 pp.

Cruz Barney, Oscar (coord.), 120 años del Código de Comercio. Codificación y Descodificación Mercantil en México, México, Ilustre y Nacional Colegio de Abogados de México-Tribunal Superior de Justicia del D. F.-UNAM, Instituto de Investigaciones Jurídicas, 2009.

Cruz BARneY, Oscar et al. (coords.), Los abogados y la formación del Estado mexicano, México, UNAM, Instituto de Investigaciones Jurídicas- 
Instituto de Investigaciones Históricas-Ilustre y Nacional Colegio de Abogados de México, 2013.

Cruz Barney, Oscar y Carbonell Sánchez, Miguel (coords.), Historia y Constitución. Homenaje a José Luis Soberanes Fernández, México, UNAM, Instituto de Investigaciones Jurídicas, 2015, 3 ts.

Cruz Barney, Oscar y Soberanes Fernández, José Luis (coords.), Historia del derecho. X Congreso de Historia del Derecho Mexicano, México, UNAM, Instituto de Investigaciones Jurídicas, 2016, 3 ts.

Cruz Barney, Oscar y Soberanes Fernández, José Luis (coords.), Los arreglos del presidente Portes Gil con la Iglesia Católica, México, UNAM, Instituto de Investigaciones Jurídicas, 2015.

Enciclopedia jurídica mexicana, t. XII: Salud, trabajo, seguridad social, historia del derecho mexicano, jurisprudencia, legislación, personas y familia, 2a. ed., coedición con Porrúa.

Ferrer Muñoz, Manuel (coord.), La imagen del México decimonónico de los visitantes extranjeros: ¿un Estado-nación o un mosaico plurinacional?, 2002, IX-376 pp.

FERRER MuÑoz, Manuel (coord.), Los pueblos indios y el parteaguas de la independencia en México, 1999, 362 pp.

Galeana, Patricia y Valencia Carmona, Salvador (coords.), Juárez jurista, México, UNAM, Instituto de Investigaciones Jurídicas, 2007.

García Ramírez, Sergio (coord.), El derecho en México: dos siglos (18102010), vol. 1: Derecho constitucional.

García Ramírez, Sergio (coord.), El derecho en México: dos siglos (18102010), vol. 2: Derecho internacional.

García Ramírez, Sergio (coord.), El derecho en México: dos siglos (18102010), vol. 3: Derecho administrativo.

García Ramírez, Sergio (coord.), El derecho en México: dos siglos (18102010), vol. 4: Derecho privado.

García Ramírez, Sergio (coord.), El derecho en México: dos siglos (18102010), vol. 5: Derecho social.

García Ramírez, Sergio (coord.), El derecho en México: dos siglos (18102010), vol. 6: Derecho procesal.

García Ramírez, Sergio (coord.), El derecho en México: dos siglos (18102010), vol. 7: Derecho penal.

García Ramírez, Sergio (coord.), El derecho en México: dos siglos (18102010), vol. 8: Historiografía del derecho, filosofía del derecho y literatura. GonZÁlez Martín, Nuria (coord.), Estudios jurídicos en homenaje a Marta Morineau, t. I: Derecho romano. Historia del derecho, 2006, XLIV-509 pp. 
Guerrero Galván, Luis René (coord.), Inquisición y derecho. Nuevas versiones de las transgresiones inquisitoriales en el nuevo mundo. Del antiguo régimen a los albores de la modernidad, México, UNAM, Instituto de Investigaciones Jurídicas, 2016.

Soberanes Fernández, José Luis (coord.), Memoria del III Congreso de Historia del Derecho Mexicano (1983), 1984, 733 pp.

Soberanes Fernández, José Luis, Los tribunales de la Nueva España (antología), 1980, $367 \mathrm{pp}$.

Soberanes Fernández, José Luis y Martínez de Codes, Rosa María, (coords.), Homenaje a Alberto de la Hera, 2008, XIII-920 pp.

Soberanes Fernández, José Luis y Ortiz Ortiz, Serafín (coords.), Los sentimientos de la nación de Morelos en Tlaxcala: Coloquio Internacional de Derecho, México, UNAM, Instituto de Investigaciones JurídicasTlaxcala, Tlax., Universidad Autónoma de Tlaxcala, 2014.

VARIOS AUTORES, A cien años de la muerte de Vallarta, 1994, 258 pp.

Varios autores, Centenario del Código de Comercio, 1991, 615 pp.

VARIOS AUTORES, Homenaje a fray Alonso de la Veracruz en el IV centenario de su muerte (1584-1984), 1986, 66 pp.

VArios aUtores, La Constitución mexicana de 1917. Ideólogos, el núcleo fundador y otros constituyentes, 1990, $515 \mathrm{pp}$.

VARIOS AUTORES, La formación del Estado mexicano, coedición con Porrúa, 1984, $300 \mathrm{pp}$.

VARIOS AUTORES, La supervivencia del derecho español en Hispanoamérica durante la época independiente, 1998, $447 \mathrm{pp}$.

Varios autores, Libro del cincuentenario del Código Civil, 1978, 351 pp.

VARIOS AUtORes, Memoria del II Congreso de Historia del Derecho Mexicano (1980), 1981, $760 \mathrm{pp}$.

VARIos autores, Memoria del X Congreso del Instituto Internacional de Historia del Derecho Indiano, coedición con la Escuela Libre de Derecho, 1995, t. I, 926 pp.

VARIOS AUTORES, Setenta y cinco años de evolución jurídica en el mundo, vol. II: Historia del derecho y derecho comparado, 1979, $191 \mathrm{pp}$.

VARIOS AUTORES, Un siglo de derecho civil mexicano. Memoria del II Coloquio Nacional de Derecho Civil, 1985, 200 pp.

\section{e) Bibliotheca Iuridica Latina Mexicana}

Se ha publicado en coedición con el Instituto de Investigaciones Filológicas de la UNAM. Sus títulos son: 
AdAme GodDARD, Jorge (trad., introd. y notas), Modestino. Respuestas. Libros I al XIX, latín-español, 1987, XXVII+42+42 pp.

Adame GodDard, Jorge (trad., notas e índice), Libro XVIII del Digesto (sobre la compraventa), latín-español, 1993, CXXXVI+95+95 pp.

Irigoyen Troconis, Martha Patricia (trad., introd., notas e índice), Paulo. Sentencias. Libro segundo Interpretatio, latín-español, 1994, CLXXXI+69+69 pp.

Irigoyen Troconis, Martha Patricia (trad., notas e índice alfabético), Julio Paulo. Sentencias a su hijo. Libro I Interpretatio, 1a. reimp., latín-español, 1995, LXXXV+49+49 pp.

Irigoyen Troconis, Martha Patricia (versión de) (trad., est. introd., anotación e índices), Sobre el significado de las palabras (Digesto 50.16), latínespañol, 1997, XLI+51+51 pp.

Irigoyen Troconis, Martha Patricia (versión de), Sobre diversas reglas del derecho antiguo (Digesto 50:17), latín-español, 2005, XXXVII+23+23 pp.

Montemayor Aceves, Martha Elena (trad., introd. e índice de palabras anotado), Comparación de leyes mosaicas y romanas, latín-español, 1994, CXLIII $+53+53 \mathrm{pp}$.

Montemayor Aceves, Martha Elena (versión de), Fragmentos vaticanos, 2003, XXV+96+96 y XXXICXLII pp.

Vargas Valencia, Aurelia (trad., introd. y notas), Consulta de un jurisconsulto antiguo, latín-español, 1991, XXVII+32+32 pp.

Con el Fondo de Cultura Económica fue publicado el importantísimo texto:

Aguiar y Acuña, Rodrigo de y Montemayor y Córdoba De Cuenca, Juan Francisco, Sumarios de la Recopilación General de Leyes de las Indias Occidentales, presentación de José Luis Soberanes Fernández, 1994, 792 pp.

IV. A MANERA DE CONCLUSIÓN. El PAPEL DEL INSTITUTO DE INVESTIGACIONES JURÍDICAS EN EL ESTUDIO Y DIFUSIÓN DE LA HISTORIA DEL DERECHO

La historia del derecho ha sido objeto de impulso constante por el Instituto de Investigaciones Jurídicas. Sin duda, la dirección del doctor José Luis Soberanes fue emblemática en ese sentido, dado su carácter de historiador del derecho, "quien tanto hizo durante su gestión por impulsar la historia del derecho, sea mediante publicaciones, organización de congresos, o intercam- 
bio de conferenciantes e investigadores, sea mediante el apoyo brindado a estudiantes mexicanos para formarse en el extranjero como historiadores del derecho". ${ }^{14}$

Afortunadamente, el apoyo a los estudios y tareas de historia del derecho se mantuvieron bajo las direcciones que le siguieron. Actualmente, el Instituto dio un paso de gran importancia en materia de rescate de literatura jurídica al hacerse atinadamente de una muy importante colección de folletería jurídica mexicana enfocada al derecho constitucional que permitirá mayores estudios histórico-jurídicos en dicha área.

En cuanto a las publicaciones histórico-jurídicas, sin menoscabo de la importante tarea que otras instituciones llevan a cabo, sin duda el papel del Instituto ha sido fundamental para la materia. ${ }^{15} \mathrm{El}$ número y la calidad de los textos publicados es una muestra clara de la importancia de ese papel. No olvidemos que la única publicación periódica dedicada exclusivamente a la Historia del derecho es responsabilidad del Instituto.

El Instituto de Investigaciones Jurídicas de la UNAM a través del Área de Historia del Derecho tiene y desempeña una responsabilidad y tarea "histórica": debe mantener e incrementar los estudios, la investigación y las publicaciones en la materia.

14 Arenal Fenochio, Jaime del, op. cit., p. 75.

15 Pensemos en las publicaciones de libros, artículos y demás obras llevadas a cabo, a manera de ejemplo, por la Universidad Iberoamericana en sus diversas sedes, la Universidad Panamericana, la Escuela Libre de Derecho, El Colegio de México, la Universidad Michoacana de San Nicolás de Hidalgo, y otras más. 